\title{
Placebo: Feeling Better, Getting Better, and the Problems of Mind and Body
}

\author{
John F. Kihlstrom*
}

\begin{abstract}
Over its history, medicine has vacillated between acknowledging placebo effects as important and trying to overcome them. Placebos are controversial, in part, because they appear to challenge a biocentric view of the scientific basis of medical practice. At the very least, research should distinguish between the effects of placebos on subjective and objective endpoints. Theoretically, placebos are of interest because they underscore the other side of the mind-body problem: how mental states can affect physical conditions.
\end{abstract}

Medicine, and the healthcare professions generally, has always had a vexed relationship with the placebo. Was it Hippocrates, or was it Galen, who enjoined physicians to use new medicines while they still had the power to heal - acknowledging that something other than the intrinsic properties of drugs was critical to their success? In any event, long before Pepper (1) and Beecher (2) drew professional attention to placebo effects, scientific physicians appreciated the importance of belief and suggestion in curing disease (for comprehensive coverage of placebo effects and related topics, see 3-7). It was not long ago that placebo pills, labeled as such, were listed in the Physicians Desk Reference. Norman Cousins (8) famously advocated placebo effects in medicine at roughly the same time that the randomized clinical trial - still the gold standard for evidence-based treatment - effectively consigned the placebo effect to the status of a nuisance variable which must be overcome, instead of a catalyst to be capitalized on. The New York Times Magazine announced on its cover (January 9, 2000) the "astonishing fact" that "placebos work". But only a year later, not content merely to show that effective treatments are better than placebo, Hrobjartsson and Gotzsche $(9,10)$ concluded that placebos had virtually

*To whom correspondence should be addressed:

John F. Kihlstrom

University of California, Berkeley

Institute for the Study of Healthcare Organizations and Transactions

Department of Psychology, MC 1650

Berkeley, California 94720-1650

Email: jfkihlstrom@berkeley.edu

Internet: http://socrates.berkeley.edu/ kihlstrm no practical effects on clinical outcome - leading the Wall Street Journal, in a May 30, 2001 commentary, to criticize the "Dale Carnegie school of medical thought". Nevertheless, the New York Times recently reported (May 27, 2008) that a Maryland-based company, Efficacy Brands, proposed to market a cherry-flavored placebo named Obecalp (read it backwards) over the counter to reduce the use of active medications for children with minor ills, hypochondriasis, and other forms of abnormal illness behavior.

Why are placebos so controversial? In part, I think, it is because they appear to challenge the biological basis of medical practice. Beginning with the microbehunting of Pasteur and Koch, through the pharmaceutical revolution, the development of laboratory diagnostics and imaging techniques, and pharmacogenomics, a major trend in the scientific revolution in medicine has been the development of diagnostic and therapeutic techniques that minimize human interaction between physician and patient. Elsewhere, I have cited the "feinberger", the handscanner used on Star Trek to diagnose and treat illness, as the apparent ideal for scientific medicine, because it obviates the need to take account of any psychosocial dimension of illness, prevention, or treatment (11). Scientific medicine, in this exclusively biocentric view, is simply a matter of treating germs with pills.

But the behavioral and social sciences are sciences too, and the placebo and related effects underscore the psychosocial dimensions of illness, prevention, and treatment: of the effect of the patient's (and the physician's) beliefs, attitudes, and expectations on the 
effects of those pills; on the role of human judgment in assessing symptoms, reading test results, making diagnoses, and choosing treatments; on the intrapersonal and interpersonal determinants of compliance, the importance of physician-patient communication and social support on treatment outcomes; the relationship between social class (and social status) and health. You can make a pill to treat an illness - that's a matter of understanding the biology, but then you've got to get the patient to take the pill and that is a matter of psychology and social science.

The fact that Hrobjartsson and Gotszche, searching the entire medical literature, were able to find only 114 studies that compared placebo to a no-treatment control is powerful testimony to the widespread lack of interest in the placebo effect as an effect - an effect that can be added to the specific effects of prescription drugs or other biological treatments. In the treatment of pain, for example, big, dark-colored, bad-tasting placebos are more effective than small, brightly colored, good tasting ones; placebos delivered intravenously are more effective than placebos delivered intramuscularly, which in turn are more effective than placebos delivered orally (12). And it appears that the effect of a placebo was a constant proportion of that of the active agent to which it was compared: placebo believed to be aspirin is roughly $55 \%$ as effective as real aspirin, but placebo believed to be morphine is roughly $55 \%$ as effective as real morphine (12). More recently, we have learned that expensive placebos are more effective than cheap ones (13). At the very least, results such as these suggest how genuine medications ought to be marketed, if we are to maximize their effectiveness.

Wampold and his colleagues suggest that placebo effects will be greatest with psychological as opposed to physical disorders - that is, for disorders like depression rather than for cancer or heart disease; and, in the case of physical disorders, when the endpoint is psychological rather than in nature - that is, for anxiety, or depression or pain rather than for coronary cardiovascular disease or for cancer (14). The implication is that the placebo effect, being "psychological" in nature, will work only on the psychological dimensions of health and disease. Certainly, there seems to be a huge placebo component in the treatment of certain psychiatric disorders, such as depression $(15,16)$. But at the same time, the medical literature is littered with convincing demonstrations that patients' beliefs and expectations can moderate drug and other biological effects on objective as well as subjective endpoints. In one recent study, for example, Parkinson's disease patients experienced higher degrees of motor control when they were told they were receiving electrical stimulation of the subthalamic nucleus than when the stimulation was delivered without their knowledge (17). So much for the feinberger. Paraphrasing the advertisements for Nexium $^{\mathrm{TM}}$, future research needs to distinguish between two types of endpoints: subjective endpoints -feeling better - and objective- getting better.

Placebo effects have been called the "crown jewel" of psychosomatic medicine, because they reveal the effects of mental states -- attitudes, beliefs, and expectations -- on physical outcomes. Psychosomatic effects, in turn, are in bad odor among some segments of the medical community for the same reason that placebo effects are: the proposition that psychosocial factors might play a causative role in physical illness is seen as compromising the basis of medicine on biological science. After Marshall \& Warren (18) identified the role of $H$. pylori in gastritis and peptic ulcers (a discovery that earned them the Nobel Prize in 2005), a leading molecular neuropsychiatrist wrote a commentary entitled "Another One Bites the Dust" (19) celebrating the triumph of biomedicine over psychology. But as it turns out, while antibodies for $H$. pylori are found in over $90 \%$ of ulcer patients, they are also found in almost $80 \%$ of ulcer-free patients, indicating that "other factors in addition to $H$. pylori infection have an important role in the development of peptic ulcer" (20). Some of these factors are psychosocial: animal models clearly show a causal role for psychological stress in the origin of ulcers (21). If both stress and bacterial infection contribute to gastric disease, then both deserve appropriate diagnosis and treatment.

But beyond whatever advantage they can provide in the treatment of illness, placebos are of theoretical interest because of the light they can shed on the problems of mind and body. Usually, the mind-body problem is framed as unidirectional: how brain processes can produce conscious mental states. But placebos, and other psychosomatic effects, remind us that there is another mind-body problem: how mental states can affect bodily functioning. Documenting these effects, and understanding their underlying psychological and biological mechanisms, is the great challenge posed by placebos.

\section{REFERENCES}

1. Pepper, O. H. A note on the placebo. American J Pharmacology. 1994; 117; 409.

2. Beecher, H. K. The powerful placebo. JAMA. 1995;159, 16021606.

3. Benedetti, F. Mechanisms of placebo and placebo-related effects across diseases and treatments. Ann Rev Pharm Tox. 2007; 48, 33-60.

4. Harrington, A. The placebo effect: An interdisciplinary exploration. Cambridge, Ma.: Harvard University Press. 1997 
5. Harrington, A. The cure within: A history of mind-body medicine. New York: Norton.2008

6. Price, D. D., Finniss, D. G., \& Benedetti, F. A comprehensive review of the placebo effect: recent advances and current thought. Annual Review of Psychology. 2008; 59: 565-590.

7. Shapiro, A. K., \& Shapiro, E. The powerful placebo: From ancient priest to modern physician. Baltimore, Md.: Johns Hopkins University press. 1997

8. Cousins, N. Anatomy of an illness (as perceived by the patient). NEJM. 1976; 295, 1458-1463.

9. Hrobjartsson, A., \& Gotzsche, P. C. Core belief in powerful effects of placebo interventions is in conflict with no evidence of important effects in a large systematic review. Advances in Mind-Body Medicine. 2001; 17: 312-318.

10. Hrobjartsson A, Gotzsche P.C. Is the placebo powerless? An analysis of clinical trials comparing placebo with no treatment. NEJM. 2001;344(21):1594-1602.

11. Kihlstrom, J. F. Expecting that a treatment will be given, when it won't, and knowing that a treatment is being given, when it is [Commentary on "Open versus hidden medical treatments: The patient's knowledge about a therapy affects therapy outcome" by F. Benedetti, G. Maggi, L. Lopiano, M. Lanotte, I. Rainero, S. Vighetti, \& A Pollo]. Prevention \& Treatment. 2003; 6: Article 4.

12. Evans, F. J The placebo response in pain reduction. In J. J. Bonica (Ed.), Advances in Neurology. New York: Raven. 1974; 289-296

13. Waber, R. L., \& al. Commercial features of placebo and therapeutic efficacy. JAMA, 2008; 299: 1-16-1017.
14. Wampold, B. E., Minami, T., Tierney, S. C., Baskin, t. W., \& Bhati, K. S. The placebo is powerful: Estimating placebo effects in medicine and psychotherapy from randomized clinical trials. J Clin Psych. 2005; 61; 835-854.

15. Kirsch, I., Moore, T. J., Scoboria, A., \& Nicholls, S. S. The emperor's new drugs: An analysis of antidepressant medication data submitted to the US Food and Drug Administration. Prevention \& Treatment. 2002; 5: Article 23.

16. Kirsch, I., \& Sapirstein, G. Listening to Prozac but hearing placebo: A meta-analysis of antidepressant medication. Prevention \& Treatment. 1998; 1: Article 2a.

17. Benedetti, F., Maggi, G., Lopiano, L., Rainero, I., Vighetti, S., \& Pollo, A. Open versus hidden medical treatments: The patient's knowledge about a therapy affects the therapy outcome. Prevention \& Treatment. 2003; 6.

18. Marshall, B. J., \& Warren, J. R. Unidentified curved bacilli in the stomach of patients with gastritis and peptic ulceration. Lancet. 1984; 1: 1311.

19. Hyman, S. E. Another one bites the dust: An infectious origin for peptic ulcers. Harvard Review of Psychiatry. 1994; 1; 294-295.

20. Nomura, A., Stemmermann, G. N., Chyou, P.-H., Perez-Perez, G. I., \& Blaser, M. J.. Helicobacter pylori infection and the risk for duodenal and gastric ulceration. Annals of Internal Medicine. 1994; 120: 977-981.

21. Overmier, J. B., \& Murison, R. Animal models reveal the "psych" in the psychosomatics of ulcers. Current Directions in Psychological Science. 1997; 6(6): 180-184.

John F. Kihlstrom graduated from Colgate University in 1970, and received his $\mathrm{PhD}$ in personality and experimental psychopathology from the University of Pennsylvania in 1975. After completing a clinical internship at Temple University Health Sciences Center, he took his first faculty position at Harvard, moving to Wisconsin, Arizona, and Yale before settling in the Department of Psychology at the University of California, Berkeley. At Berkeley, he teaches in the Cognition, Brain and Behavior and Social/Personality graduate programs, and is a member of the Institute of Cognitive and Brain Sciences and the Institute of Personality and Social Research. He is currently director of the undergraduate group major in cognitive science. Kihlstrom's research interests include unconscious mental life, the human ecology of memory, hypnosis, and social cognition. 